\title{
Neurosurgery training in India during the COVID-19 pandemic: straight from the horse's mouth
}

\author{
${ }^{*}$ Chinmaya Dash, MCh, ${ }^{1}$ Tejas Venkataram, MS, ${ }^{2}$ Nishant Goyal, MCh, ${ }^{2}$ Jitender Chaturvedi, MCh, ${ }^{2}$ \\ Amol Raheja, MCh, ${ }^{3}$ Raghav Singla, $\mathrm{MCh},{ }^{4}$ Jayesh Sardhara, $\mathrm{MCh},{ }^{5}$ and Ravi Gupta, $\mathrm{MD}^{6}$
}

\begin{abstract}
1Department of Neurosurgery, All India Institute of Medical Sciences, Bhubaneshwar, Orissa; '2Department of Neurosurgery, All India Institute of Medical Sciences, Rishikesh, Uttarakhand; ${ }^{3}$ Department of Neurosurgery, All India Institute of Medical Sciences, New Delhi; ${ }^{4}$ Department of Neurosurgery, Post Graduate Institute of Medical Education and Research, Chandigarh; ${ }^{5}$ Department of Neurosurgery, Sanjay Gandhi Post Graduate Institute of Medical Sciences, Lucknow; and ${ }^{6}$ Department of Psychiatry, All India Institute of Medical Sciences, Rishikesh, Uttarakhand, India
\end{abstract}

OBJECTIVE The COVID-19 pandemic has forced medical professionals throughout the world to adapt to the changing medical scenario. The objective of this survey was to assess the change in neurosurgical training in India following the COVID-19 pandemic.

METHODS Between May 7, 2020, and May 16, 2020, a validated questionnaire was circulated among neurosurgical residents across India by social media, regarding changes in the department's functioning, patient interaction, surgical exposure, changes in academics, and fears and apprehensions associated with the pandemic. The responses were kept anonymous and were analyzed for changes during the COVID-19 pandemic compared to before the pandemic.

RESULTS A total of 118 residents from 29 neurosurgical training programs across 17 states/union territories of the country gave their responses to the survey questionnaire. The survey revealed that the surgical exposure of neurosurgical residents has drastically reduced since the onset of the COVID-19 pandemic, from an average of 39.86 surgeries performed/assisted per month (median 30) to 12.31 per month (median 10), representing a decrease of $67.50 \%$. The number of academic sessions has fallen from a median of 5 per week to 2 per week. The survey uncovered the lack of universal guidelines and homogeneity regarding preoperative COVID-19 testing. The survey also reveals reluctance toward detailed patient examinations since the COVID-19 outbreak. The majority of respondents felt that the COVID-19 pandemic will hamper their operative and clinical skills. Fear of rescheduling or deferring of licensing examinations was significantly higher among those closest to the examination $(p=0.002)$.

CONCLUSIONS The adverse impact of the pandemic on neurosurgical training needs to be addressed. While ensuring the safety of the residents, institutes and neurosurgical societies/bodies must take it upon themselves to ensure that their residents continue to learn and develop neurosurgical skills during these difficult times.

https://thejns.org/doi/abs/10.3171/2020.9.FOCUS20537

KEYWORDS COVID-19; neurosurgical training; neurosurgical residency; India

$\mathrm{T}$ HE coronavirus disease of 2019 (COVID-19) is a global pandemic that has had a severe impact on healthcare globally. The healthcare infrastructure has been made to adapt to this medical crisis globally with modifications in our daily practice. Despite the country's huge population and limited healthcare resources, India has managed to keep the total count of COVID-19 patients to fewer than 200,000 at the time of writing this article (June 3, 2020). ${ }^{1}$ However, the country needs to prepare itself for the greater challenges ahead as the number of cases are expected to rise exponentially. Healthcare workers in India have adapted to this crisis based on the information and updates given by the Indian Council of Medical Research and government agencies. Gupta et al. recently published a consensus statement for the neurosurgeons and neurologists of the country. ${ }^{2}$ Several recommendations were made regarding categorizing patients based on priority, avoiding nonessential elective surgeries and outpatient clinics after informing patients, and making changes in the operating room, along with training in wearing personal protective equipment (PPE). The pandemic, apart from drastically changing the way neurosurgery is practiced, has had a serious effect on neurosurgical training programs across the country.

In this article, we have tried to analyze the trials and

ABBREVIATIONS OPD = outpatient department; PPE = personal protective equipment; SARS = severe acute respiratory syndrome.

SUBMITTED June 4, 2020. ACCEPTED September 24, 2020.

INCLUDE WHEN CITING DOI: 10.3171/2020.9.FOCUS20537.

${ }^{*}$ C.D., T.V., and N.G. contributed equally to this study and share first authorship. 


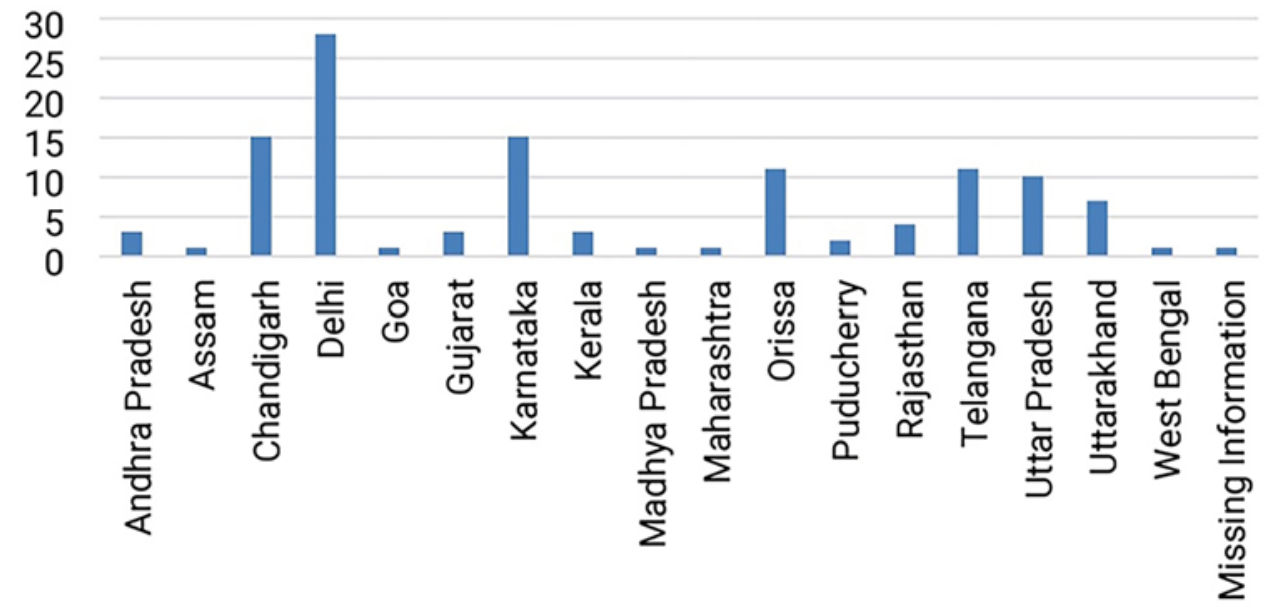

FIG. 1. Bar graph representing the number of respondents according to states or union territories of India.

tribulations faced by neurosurgical residents throughout India during these difficult times. We then proceed to discuss possible solutions to hurdles and alternatives that can help neurosurgical residents keep up with the ever-changing world of neurosurgery. The aim of this article is to bring the viewpoint of residents regarding neurosurgical training and neurosurgical practice at the grassroots level to the attention of various stakeholders.

\section{Methods}

\section{Designing and Validating the Survey Questionnaire}

A cross-sectional study was conducted using an online survey questionnaire circulated from May 7, 2020, to May 16,2020 . For this purpose, a well-constructed questionnaire was designed by the authors on the website www.googleforms.com. Face validity was conducted by two medical professionals. For content validity, the questionnaire was sent via email to a total of 4 subject experts ( 2 neurosurgery residents and 2 consultant neurosurgeons) and they were asked to rate each question individually on the basis of relevance on a scale of 1-4 (Supplementary Material 1). Using their feedback, the Item-Content Validity Index (I-CVI) of 1 was calculated and a Scale-level-Content Validity Index (S-CVI/Ave) of 1 was calculated (Supplementary Material 2). ${ }^{3}$ Furthermore, any feedback of the experts deemed relevant to the article by the authors was accepted and necessary changes to the questionnaire were made.

\section{Final Questionnaire}

The final questionnaire (Supplementary Material 3) comprised seven sections, including 36 questions. After briefly explaining the purpose of the survey, the resident's consent was sought and those consenting to participate in the survey filled in the answers to all of the questions. The first section comprised the respondents' demographic details. The second section contained questions related to COVID-19-related duties, i.e., provision for quarantine and PPE. The third section included questions regarding their departments' functioning and methods of conducting outpatient department (OPD) and preoperative COVID-19 testing. The fourth section addressed changes in doctorpatient interaction due to COVID-19. It contained questions related to patient examination and opinions regarding patient screening for COVID-19. The fifth section compared the number of surgeries before and during the pandemic and the effect of PPE on surgical performance. The sixth section contained questions pertaining to academics and research. The last section covered the impact of COVID-19 on the respondents' fears and apprehensions regarding their training and future due to the pandemic.

The link to the questionnaire was widely circulated among the social media groups of residents undergoing neurosurgical training in various institutions of the country. All of them were completely anonymized to ensure a frank response. They were asked to forward the questionnaire to their colleagues, thus using the "snowball technique" for survey recruitment to limit selection bias.

\section{Results}

A total of 118 neurosurgical residents participated in the survey. Seventy-two (61\%) of these responses were obtained on May 10, 2020, and May 11, 2020 (Sunday and Monday).

\section{Section 1: Demographic Profile}

There were a total of 118 respondents (113 males, 5 females) from 29 neurosurgery training programs, with good representation from all over the country, including 17 states/union territories (Fig. 1). This included both post-MS 3-year-course residents as well as post-MBBS 6 -year-course residents who were scheduled for licensing examinations between July 2020 and July 2024 (Fig. $2)$. Most respondents $(\mathrm{n}=104,88.14 \%)$ worked in institutions that treated both COVID-19 and non-COVID-19 patients; 10 respondents $(8.47 \%)$ worked at institutions treating non-COVID-19 patients only, while 4 respondents (3.39\%) worked at institutions treating COVID-19 patients exclusively. Most respondents $(n=96,81.36 \%)$ felt that as neurosurgeons, they had a role to play in battling the COVID-19 pandemic. Fifty-six respondents (47.46\%) had been posted in COVID-19-related duties (Table 1). 


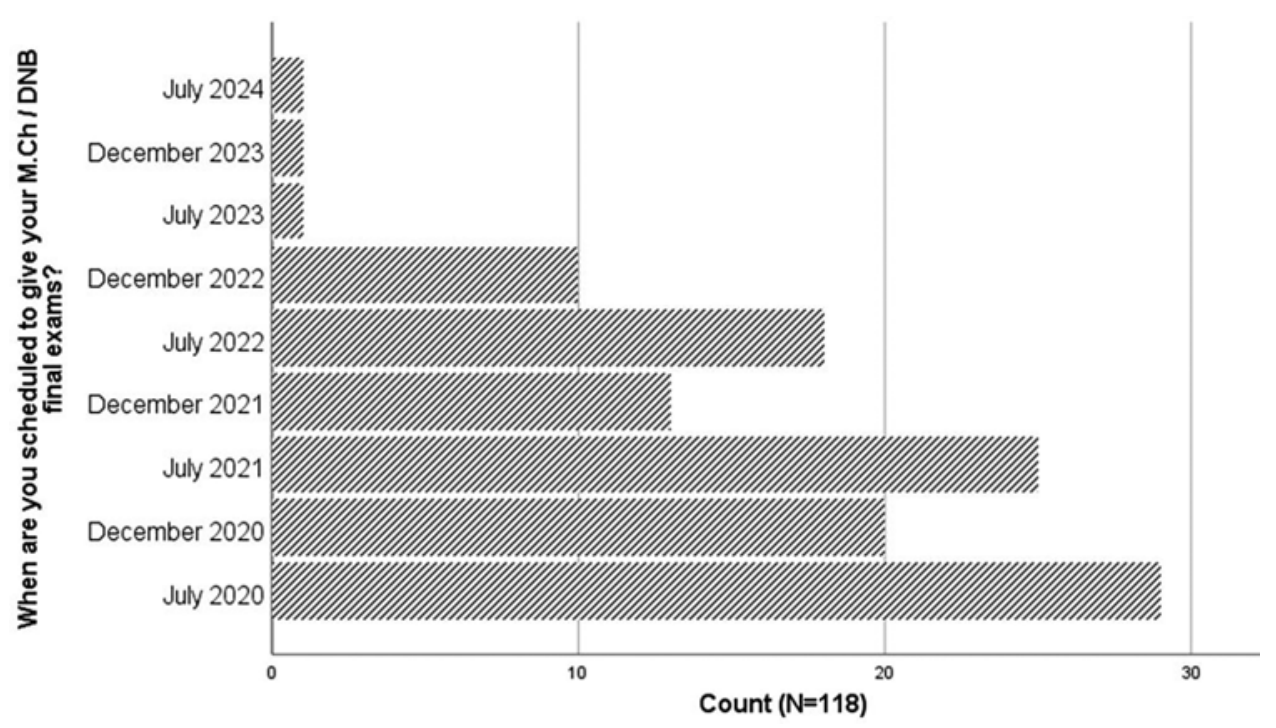

FIG. 2. Horizontal bar graph representing the number of respondents according to when they are scheduled for neurosurgical licensing examinations.

\section{Section 2: Provision of PPE and Postduty Quarantine Period}

Of the 56 respondents posted in COVID-19-related duties, 44 respondents $(78.57 \%)$ were provided quarantine periods that the respondents considered adequate, and 47 respondents $(83.93 \%)$ were of the opinion that they were provided with adequate PPE (Table 1).

\section{Section 3: Staffing Pattern, Manner of Conducting OPD, and Preoperative COVID-19 Testing}

Overall, the departments of most respondents $(n=94$, $79.66 \%)$ worked with reduced staffing. Fifty respondents (42.37\%) had switched over to telemedicine exclusively for OPD services. Nineteen respondents $(16.10 \%)$ worked in departments that were not conducting OPDs at all, and 36 respondents $(30.51 \%)$ worked in institutions that were running physical OPDs exclusively. Thirteen respondents $(11.02 \%)$ were conducting both physical OPDs and telemedicine. Regarding preoperative COVID-19 testing in their setting, $58(49.15 \%)$ responded by saying that no preoperative COVID-19-negative report was required, 50 $(42.37 \%)$ responded that one negative sample was required, and $10(8.47 \%)$ responded that two negative samples were required. When asked about their opinion regarding which neurosurgical patients should be tested for COVID-19, 30 respondents $(25.42 \%)$ wanted testing for all patients visiting OPDs, 85 (72.03\%) wanted testing for all patients getting admitted, $18(15.25 \%)$ wanted it only for patients planned for elective surgery, 15 (12.71\%) wanted it only for patients planned for emergency surgery, and $83(70.3 \%)$ wanted testing for patients at high risk for COVID-19 (Table 2).

\section{Section 4: Patient-Doctor Interaction During COVID-19 Pandemic}

When asked if they examined patients in as much detail as before the pandemic, $48(40.68 \%)$ responded in the affirmative. When specifically asked if during the pandemic they would test a patient's gag reflex when indicated, 50 (42.37\%) responded in the affirmative. Most respondents ( $n=104,88.14 \%)$ were of the opinion that patients' elective surgeries should not be performed during the pandemic (Table 2).

\section{Section 5: Change in the Number of Surgeries Performed/ Assisted and PPE Use During Surgery}

There was a significant decrease in the number of surgeries performed during the COVID-19 pandemic as compared to the pre-COVID-19 era. Our respondents used to perform/assist an average of 39.86 surgeries a month (median 30, range 0-150 surgeries) before the onset of COVID-19. During the pandemic, this average has fallen to 12.31 surgeries per month (median 10, range 0-90 surgeries). This represents a decline of $67.50 \%$ in the average number of surgeries performed/assisted per month during the COVID-19 pandemic ( $p<0.0001$; Fig. 3). Regarding use of PPE during surgery, the majority $(n=61$, $51.69 \%$ ) were of the opinion that wearing PPE adversely affected their surgical performance, while $8(6.78 \%)$ felt that it made no difference and 4 (3.39\%) reported a positive impact. A significant number of our respondents (n $=45,38.14 \%$ ) had never used PPE during their surgeries (Table 2).

\section{Section 6: Academics During COVID-19}

There was a reduction in the number of academic sessions per week for the responding residents during the pandemic. From a median of 5 academic sessions/week (mean 4.86 sessions) during the pre-COVID-19 era, the number of academic sessions declined to a median of 2 (mean 2.97 sessions), amounting to a decline of $32.60 \%$ (p $<0.0001$; Fig. 4). A major shift from classroom teaching $(\mathrm{n}=30,25.42 \%)$ to online videoconferencing sessions ( $\mathrm{n}$ $=72,61.02 \%$ ) was observed in the survey. Academic sessions had stopped according to 16 respondents (13.56\%). 
TABLE 1. Demographic details of respondents, and questions regarding COVID-19-related duties

\begin{tabular}{|c|c|c|}
\hline Variable & Value & $\%$ \\
\hline \multicolumn{3}{|l|}{ Gender } \\
\hline Male & 113 & 95.76 \\
\hline Female & 5 & 4.24 \\
\hline \multicolumn{3}{|l|}{ Hospital currently treats } \\
\hline Only COVID-19 patients & 4 & 3.39 \\
\hline Only non-COVID-19 patients & 10 & 8.47 \\
\hline Both & 104 & 88.14 \\
\hline \multicolumn{3}{|c|}{$\begin{array}{l}\text { As a neurosurgeon, do you feel you have a role } \\
\text { to play in battling the COVID-19 pandemic? }\end{array}$} \\
\hline Yes & 96 & 81.36 \\
\hline No & 22 & 18.64 \\
\hline \multicolumn{3}{|l|}{ Posted in COVID-19-related duties } \\
\hline Yes & 56 & 47.46 \\
\hline No & 62 & 52.54 \\
\hline \multicolumn{3}{|c|}{$\begin{array}{l}\text { Are you provided with adequate PPE while } \\
\text { working in COVID-19-related duties? }\end{array}$} \\
\hline Yes & $47 / 56$ & 83.93 \\
\hline No & $9 / 56$ & 16.07 \\
\hline \multicolumn{3}{|c|}{$\begin{array}{l}\text { Are quarantine periods being provided following } \\
\text { periods of work in COVID-19-related duties? }\end{array}$} \\
\hline Yes & $44 / 56$ & 78.57 \\
\hline No & $12 / 56$ & 21.43 \\
\hline Total sample size & 118 & 100 \\
\hline
\end{tabular}

When asked to choose the modality of their choice for having academic sessions during the ongoing pandemic, an overwhelming number of residents $(\mathrm{n}=89,75.42 \%)$ opted for videoconferencing. Twenty-four (20.34\%) of the residents preferred academics to be stopped until the pandemic was relatively controlled. A majority of the respondents $(\mathrm{n}=53,44.91 \%)$ said teaching rounds occurred less frequently, and $48(40.68 \%)$ reported that they had stopped since the onset of the pandemic (Table 3 ).

Most of the respondents $(\mathrm{n}=88,74.58 \%)$ replied that the COVID-19 pandemic had adversely affected the research work or thesis they were pursuing. Eighty-six respondents $(72.89 \%)$ replied that a conference that they had planned to attend had been cancelled due to the current situation. When asked how they were spending their extra time academically during the lockdown while not on duty, 99 respondents $(83.90 \%)$ said they were studying, while $51(43.22 \%)$ were spending time working on publications, and $87(73.73 \%)$ said they were attending classes/webinars. When asked what improvements they would like to see in webinars, most preferred simpler topics catering to residents $(\mathrm{n}=86,72.88 \%)$, while $16(13.56 \%)$ chose longer duration, 35 (29.66\%) chose shorter duration, 55 (46.61\%) wanted content in more detail, and 12 (10.17\%) wanted content in less detail. A majority of the respondents $(\mathrm{n}=$ $69,58.47 \%$ ) preferred the academic sessions be conducted by their respective departments over third-party webinars (Table 3).
TABLE 2. Impact of the COVID-19 pandemic on departmental functioning, patient examinations, and surgeries

\begin{tabular}{lcc}
\hline \multicolumn{1}{c}{ Variable } & Value & $\%$ \\
\hline $\begin{array}{l}\text { Does your department work with reduced staffing? } \\
\text { Yes }\end{array}$ & 94 & 79.66 \\
\hline No & 24 & 20.34 \\
\hline $\begin{array}{l}\text { Does your department conduct OPDs } \\
\text { during the pandemic? }\end{array}$ & \\
\hline $\begin{array}{l}\text { Yes, physical OPD } \\
\text { Yes, telemedicine }\end{array}$ & 50 & 30.51 \\
\hline Both & 13 & 11.02 \\
\hline No & 19 & 16.10 \\
\hline
\end{tabular}

Regarding COVID-19 screening prior to surgery your department requires

\begin{tabular}{|lrr|}
\hline No COVID-19-negative samples & 58 & 49.15 \\
\hline 1 COVID-19-negative sample & 50 & 42.37 \\
\hline 2 COVID-19-negative samples & 10 & 8.47 \\
\hline Which patients should be tested for COVID-19? & & \\
\hline All patients visiting the OPD & 30 & 25.42 \\
\hline All patients getting admitted & 85 & 72.03 \\
\hline Patients planned for elective surgery only & 18 & 15.25 \\
\hline Patients planned for emergency surgery only & 15 & 12.71 \\
\hline Patients at a high risk of COVID-19 & 83 & 70.34 \\
\hline None of the patients & 0 & 0 \\
\hline
\end{tabular}

Do you examine patients in as much detail as before the pandemic?

$\begin{array}{lll}\text { Yes } & 48 & 40.68 \\ \text { No } & 70 & 59.32\end{array}$

Would you perform the gag reflex when indicated,

during the pandemic?

\begin{tabular}{lrr} 
Yes & 50 & 42.37 \\
\hline No & 68 & 57.63
\end{tabular}

Should elective surgeries continue during the pandemic?

$\begin{array}{lrr}\text { Yes } & 14 & 11.86 \\ \text { No } & 104 & 88.14\end{array}$

How does performing surgeries in PPE affect your

surgical performance?

\begin{tabular}{lrr}
\hline Positively & 4 & 3.39 \\
\hline Adversely & 61 & 51.69 \\
\hline No difference & 8 & 6.78 \\
\hline Not operated in PPE & 45 & 38.14 \\
\hline
\end{tabular}

\section{Section 7: Fears and Apprehensions Regarding the Impact of COVID-19 on Residency Programs}

A majority of the respondents $(n=104,88.14 \%)$ felt that the pandemic had an impact on their operative and clinical skills. Similarly, most of the respondents $(n=63,53.39 \%)$ felt that as a result of the pandemic they would end up being less competent than their predecessors or successors who would not have any impact on their residency due to the pandemic. Sixty-eight (57.63\%) had an apprehension of rescheduling/postponement of their examinations. The 


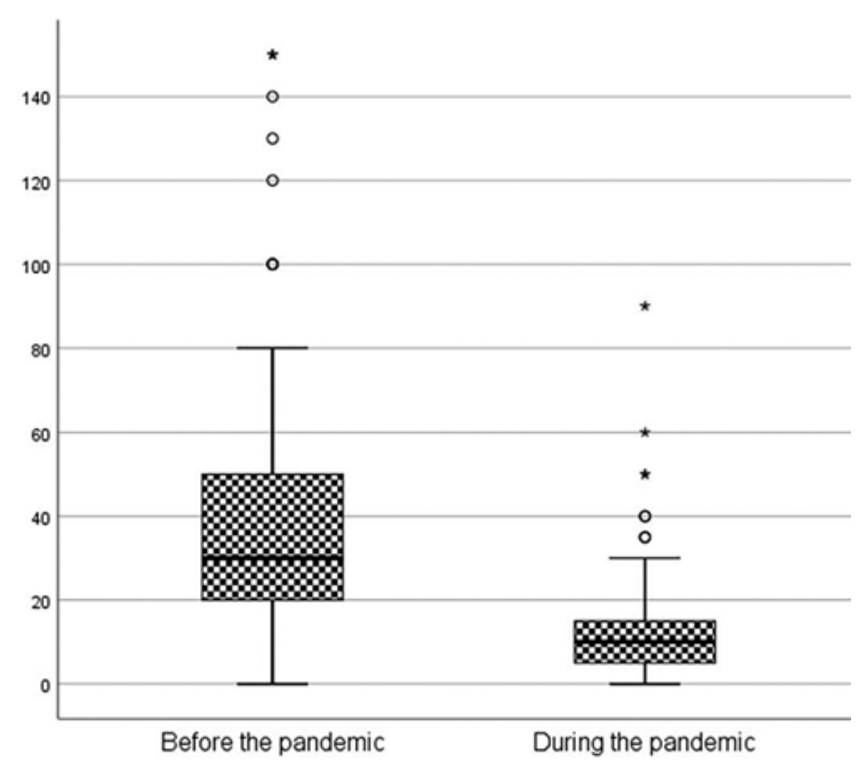

FIG. 3. Box-and-whisker plot depicting the number of surgeries performed/assisted by resident respondents during the pandemic as compared to before the pandemic. The line in the middle of each bar represents the median. An average of 39.86 surgeries were performed/ assisted per month before the pandemic, as opposed to 12.31 during the pandemic, representing a decrease of $67.50 \%(p<0.0001)$.

apprehension of rescheduling/postponement of examination was significantly higher among the respondents closer to their final exit examinations, and this finding was statistically significant $(\mathrm{p}=0.002)$. There was an apprehension of adverse effects on future job prospects/fellowship opportunities in $61(51.69 \%)$ of the respondents (Table 4).

When asked how they would compensate for the loss in training, 45 (38.13\%) responded by saying that they would extend their stay as a resident following completion of their tenure, $61(51.69 \%)$ would want to complete a fellowship, and 66 (55.93\%) said they would study more. When asked about the effect of the pandemic on workrelated stress, $57(48.30 \%)$ said it has increased, while 44 (37.29\%) said it has decreased, and $17(14.41 \%)$ said it was the same (Table 4).

\section{Discussion}

The current medical scenario is a tightrope walk. The residency programs must find the right balance between patient care and resident education. Patient examination, hands-on surgical education, didactic conferences/lectures, and research are critical to the training of neurosurgical residents. Due to the ongoing COVID-19 pandemic, patient interaction and surgical exposure have decreased substantially, didactics have been cancelled, and research work has been affected. The residency programs around the world have been faced with the challenge to adapt to keep the education going and at the same time protect our residents from themselves getting infected while discharging their duties.

Only once in recent history has any pandemic affected medical training to such a great extent. The severe acute

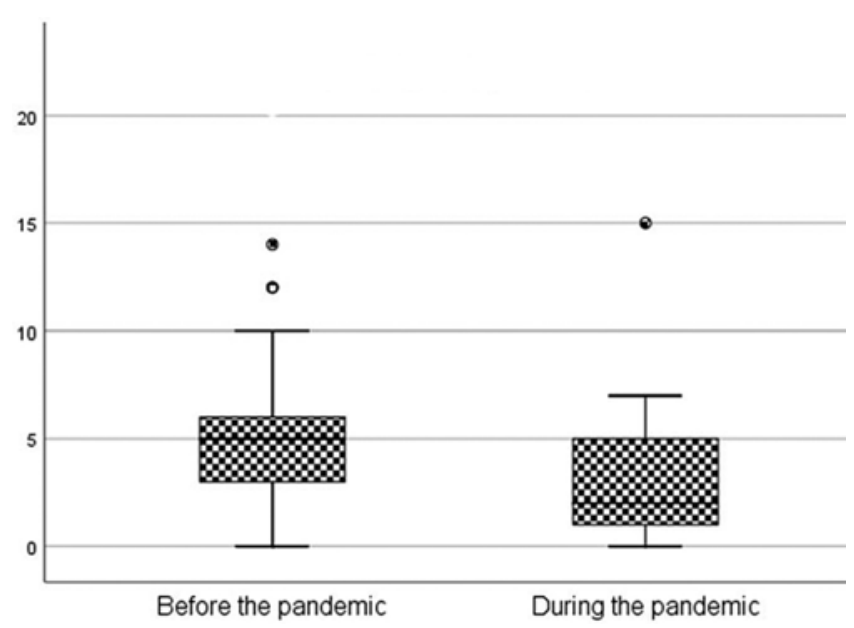

FIG. 4. Box-and-whisker plot depicting the number of academic sessions conducted by departments during the pandemic as compared to before the pandemic. The line in the middle of each bar represents the median. Before the pandemic, an average of 4.86 academic sessions (median 5 sessions) were conducted per week, while during the pandemic this average dropped to 2.97 sessions (median 2 sessions), representing a decrease of $32.60 \%(p<0.0001)$.

respiratory syndrome (SARS) epidemic in 2003 had forced authorities in Hong Kong to suspend conventional academics and make a transition to a recorded lecture format. ${ }^{4}$ Sherbino and Atzema, residents in the emergency department, described the impact of the SARS epidemic on resident training: elective cases were halted, staff were screened for fevers and symptoms at the entrance, out-ofcity services were suspended, and in-person conferences were eliminated. ${ }^{5}$ The COVID-19 pandemic has overshadowed the SARS epidemic, and this article tries to obtain the neurosurgery residents' perspective regarding patient care and resident training during the pandemic.

The authors were able to obtain 118 responses from neurosurgery residents with good distribution from all over the country. The availability of adequate PPE is a major concern for healthcare workers, not only in India, but all across the world. ${ }^{6}$ Gupta et al. have prescribed the use of N95 masks, face shields, hospital scrubs, hair covers, and gloves while examining patients. ${ }^{2}$ Donning and doffing of PPE is a time-consuming process, prone to errors, and requires training. ${ }^{5}$ Also, breathing difficulties and fogging of face shields/eye goggles hinder the smooth performance of surgeries and/or interventional procedures. ${ }^{4}$ In our study, almost $40 \%$ of residents have not operated in PPE and another 51.7\% of residents felt that their intraoperative surgical performance was affected adversely by wearing PPE. These data indicate the shortage in the availability of PPE and also the need to make them more comfortable.

Mascha et al. proposed a pandemic staffing pattern with 12-hour shifts for 7 days every other week in intensive care unit settings. ${ }^{7}$ In their hypothesized model, working with reduced staff in this way takes care of healthcare worker shortages. This pattern of reduced staffing with rotation makes sense in view of the incubation period of the coronavirus being 6.4 days, ranging from 2.1 to 11.1 days 
TABLE 3. Impact of the COVID-19 pandemic on academics

\begin{tabular}{|c|c|c|}
\hline Variable & Value & $\%$ \\
\hline \multicolumn{3}{|l|}{$\begin{array}{l}\text { What platform does your department use to } \\
\text { conduct academic sessions? }\end{array}$} \\
\hline Classroom & 30 & 25.42 \\
\hline Videoconference & 72 & 61.02 \\
\hline Stopped & 16 & 13.56 \\
\hline \multicolumn{3}{|c|}{$\begin{array}{l}\text { In your opinion, which is the best way to conduct } \\
\text { academic sessions during the pandemic? }\end{array}$} \\
\hline Classroom & 5 & 4.24 \\
\hline Videoconference & 89 & 75.42 \\
\hline Best to temporarily withhold classes & 24 & 20.34 \\
\hline \multicolumn{3}{|l|}{ Teaching rounds during the pandemic } \\
\hline Have stopped & 48 & 40.68 \\
\hline Occur less frequently & 53 & 44.91 \\
\hline Occur at the same frequency & 13 & 11.02 \\
\hline Occur more frequently & 4 & 3.39 \\
\hline \multicolumn{3}{|c|}{$\begin{array}{l}\text { Has the pandemic affected any research work you } \\
\text { are pursuing? }\end{array}$} \\
\hline Yes & 88 & 74.58 \\
\hline No & 30 & 25.42 \\
\hline \multicolumn{3}{|c|}{$\begin{array}{l}\text { Has a conference that you had planned to attend } \\
\text { been cancelled due to the COVID-19 pandemic? }\end{array}$} \\
\hline Yes & 86 & 72.89 \\
\hline No & 32 & 27.12 \\
\hline \multicolumn{3}{|l|}{$\begin{array}{l}\text { How are you spending your time in lockdown } \\
\text { academically? }\end{array}$} \\
\hline Self-study & 99 & 83.90 \\
\hline Scientific writing/publications & 51 & 43.22 \\
\hline Attending classes/webinars & 87 & 73.73 \\
\hline \multicolumn{3}{|c|}{$\begin{array}{l}\text { What improvements to third-party webinars would } \\
\text { you like to see? }\end{array}$} \\
\hline Content in more detail & 55 & 46.61 \\
\hline Content in less detail & 12 & 10.17 \\
\hline Longer duration & 16 & 13.56 \\
\hline Shorter duration & 35 & 29.66 \\
\hline Simpler subjects catering to residents & 86 & 72.88 \\
\hline \multicolumn{3}{|c|}{$\begin{array}{l}\text { Do you find third-party webinars to be better than } \\
\text { the academic sessions held by your department? }\end{array}$} \\
\hline Yes & 49 & 41.53 \\
\hline No & 69 & 58.47 \\
\hline
\end{tabular}

(2.5th-97.5th percentile of the incubation period). ${ }^{8}$ In our study, almost $80 \%$ of respondents worked with a reduced staffing pattern.

The prime minister of India, Mr. Narendra Modi, in his address to the nation while announcing a lockdown, advised patients to avoid crowding the hospitals in the country for minor ailments and elective procedures to prevent the spread of COVID-19.9 The surgeon general of the US, Dr. Jerome Adams, recommended stopping elective procedures due to the COVID-19 outbreak. ${ }^{10}$ Most hospitals around the world have seen a significant drop in elective or
TABLE 4. Fears and apprehensions of residents caused by the COVID-19 pandemic

\begin{tabular}{|c|c|c|}
\hline Variable & Value & $\%$ \\
\hline \multicolumn{3}{|c|}{$\begin{array}{l}\text { Do you feel the COVID-19 pandemic has adversely } \\
\text { impacted your neurosurgical training in terms of } \\
\text { clinical and operative skills? }\end{array}$} \\
\hline Yes & 104 & 88.14 \\
\hline No & 14 & 11.86 \\
\hline \multicolumn{3}{|c|}{$\begin{array}{l}\text { Do you fear that the COVID- } 19 \text { pandemic will render } \\
\text { you less competent than those who did not face the } \\
\text { pandemic during their residency? }\end{array}$} \\
\hline Yes & 63 & 53.39 \\
\hline No & 55 & 46.61 \\
\hline \multicolumn{3}{|c|}{$\begin{array}{l}\text { Do you fear that your exams will be rescheduled/ } \\
\text { deferred? }\end{array}$} \\
\hline Yes & 68 & 57.63 \\
\hline No & 50 & 42.37 \\
\hline \multicolumn{3}{|c|}{$\begin{array}{l}\text { Do you feel that this time lost in training will affect } \\
\text { your future job prospects/fellowship opportunities? }\end{array}$} \\
\hline Yes & 61 & $51.6 \varsigma$ \\
\hline No & 57 & 48.31 \\
\hline \multicolumn{3}{|c|}{$\begin{array}{l}\text { How do you plan on compensating for this loss in } \\
\text { training? }\end{array}$} \\
\hline Extended stay as resident & 45 & 38.13 \\
\hline Fellowship & 61 & $51.6 s$ \\
\hline Study more & 66 & 55.93 \\
\hline \multicolumn{3}{|c|}{$\begin{array}{l}\text { How has the COVID } 19 \text { pandemic impacted your } \\
\text { work-related stress? }\end{array}$} \\
\hline Increased & 57 & 48.30 \\
\hline Reduced & 44 & 37.29 \\
\hline Same & 17 & 14.41 \\
\hline
\end{tabular}

nonessential surgical volume. ${ }^{9,11-22}$ In various neurosurgical centers, functional neurosurgery, unruptured aneurysm surgery, spine surgery, benign tumors, and other less urgent surgical cases have been postponed. ${ }^{12}$ A majority of residents $(88 \%)$ in the present study were of the view that elective surgeries should be postponed during COVID-19. A shortage of PPE has resulted in residents not being able to scrub for surgeries or being asked to stay out of the operating room altogether. ${ }^{12,23}$ During the COVID-19 pandemic, a two-thirds reduction in the number of surgeries performed/assisted by the residents was observed in our survey. This will compromise the surgical exposure required for adequate training of neurosurgery residents.

There is no unanimity in the protocol for COVID-19 testing prior to conducting neurosurgical cases in our country. Nearly half of the respondents did not get preoperative COVID-19 tests. Approximately $42 \%$ of the respondents obtained one COVID-19 test prior to surgery. This reflects the confusion among the residents regarding the need/ number of preoperative COVID-19-negative samples. Given the low sensitivity (71\%) of the available COVID-19 test (antigen reverse transcriptase-polymerase chain re-

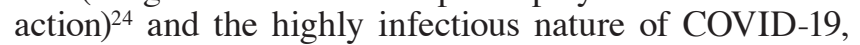


even one negative test is not enough to keep healthcare workers safe. ${ }^{25}$ Another issue dictating government and hospital policies regarding preoperative COVID-19 testing is the shortage of swab-test supplies, a problem faced worldwide. $^{26,27}$ To overcome this obstacle, numerous solutions are being pursued, such as using indigenously manufactured swabs to avoid import costs and 3D printing of swabs. ${ }^{28,29}$ The Centers for Disease Control and Prevention has been testing enzyme-linked immunosorbent assay-based antibody serology to reduce the overreliance on swab tests. With a specificity of $99 \%$ and a sensitivity of $96 \%$, serological tests look promising. However, the performance of commercial serological tests is still unproven and guidelines for their use are still awaited..$^{30}$

Telemedicine has been widely used across the world during the COVID-19 pandemic to treat patients while maintaining social distancing and quarantine measures..$^{12,14,19,20,22,31-34}$ Approximately 42\% of the residents who responded to this survey had shifted completely from physical OPDs to telemedicine. A significant proportion of residents $(42.37 \%)$ were of the opinion that they would continue to perform clinical tests such as the gag reflex, which are likely to generate more aerosols. However, our study revealed that almost $60 \%$ of the residents do not examine patients in as much detail as they did before the pandemic. The fear of contracting the virus is affecting patient interaction and examination, and hence hampering the development of clinical skills. In addition, teaching rounds have been stopped completely, as reported by $40.7 \%$ of our respondents.

Research work has been affected adversely during the pandemic: ${ }^{35}$ almost $75 \%$ of residents in our survey felt that their research or thesis work was hampered. In a survey conducted on neurosurgeons in 96 countries across six continents, El Ghandour et al. have reported that more than half of neurosurgeons worldwide have faced suspension of scientific activities, and more than a quarter have faced a cessation of research work. They also observed that the cancellation of academic activities was more likely among neurosurgeons in the Americas and Europe, while research was more often hampered in low-income nations. ${ }^{36}$ This is an interesting finding, which is probably due to already low research funding in low-income nations. Virtually all conferences of organized neurosurgical societies around the world have been either cancelled or postponed. ${ }^{37}$ The 2020 AANS Annual Scientific Meeting was cancelled for the first time since World War II. ${ }^{23}$ Almost three-fourths of the residents in our survey had planned to attend a conference that got cancelled due to the ongoing pandemic.

Third-party webinars have become commonplace during the pandemic to compensate for the cancellation of conferences. They serve as a good "substitute teacher" at a time when classroom teaching is impractical. However, a majority of our respondents preferred classes conducted by their respective institutes. This is probably due, in part, to the personal attention provided and personal relations between residents and faculty. It also indicates the difference between active and passive learning. Sixty-one percent of our respondents said that their departments used videoconferencing to conduct academic sessions. When asked regarding their preferred method of conducting aca- demic sessions during the pandemic, almost three-fourths chose videoconferencing. The adaptation from traditional classroom teaching to teleconferencing as a response to the ongoing pandemic is evident from our survey and has also been observed around the world. ${ }^{12,14,15,22,32}$

Resident training is expected to be impacted negatively, and this has manifested in the form of apprehension among the residents involved in the survey. The decreased patient interaction, decreased number of operations performed/assisted, and adverse effect on research and academics during the pandemic have made most residents $(88 \%)$ believe that their operative and clinical skills will be impacted adversely, and more than half fear that they will end up being less competent than residents of pre-COVID-19 or post-COVID-19 eras. This is a revealing finding, and there should be concerted efforts among all the academic institutions in the world to try to improvise and make up for the training time lost due to the pandemic.

The more widespread use of videoconferencing and online resources has great potential for neurosurgical education and collaborative research nationally and globally for scientific exchange and knowledge. ${ }^{22}$ The Neurosurgical Atlas, an online multimedia resource focused on operative techniques and microsurgical anatomy, has seen a more than $20 \%$ increase in web traffic since the beginning of the pandemic. ${ }^{23}$ The Congress of Neurological Surgeons has developed and distributed complimentary online education modules; grand rounds webinars; and live, interactive, virtual visiting professor sessions. ${ }^{38}$ The Neurosurgery Education and Training School is an Indian online resource, developed by the All India Institute of Medical Sciences, New Delhi, for continued neurosurgical education. ${ }^{39}$ Such dedicated modules, simulating the day-to-day academics and comprehensive coverage of topics, may be more interesting and useful for residents than the webinars.

\section{Conclusions}

This is a first-of-its-kind survey on Indian neurosurgical residents dealing with the effects of the COVID-19 pandemic on the day-to-day patient care, academics, and their concerns regarding their professional careers in the future. The responses to the various questions can be used to build a robust online academic platform to continue the academic programs in a more structured and meaningful manner, as well as address the various concerns raised by the neurosurgery residents in their practice and their future prospects.

\section{Acknowledgments}

We wish to acknowledge the role of Dr. Saquib Azad Siddiqui, Dr. Gaurang Vaghani, Dr. Aditya Patil, and Dr. Punit Kumar in the process of content validation of the survey questionnaire. We acknowledge the role of Dr. Yamini Kansal and Dr. Mandara Muralidhar Harikar in the process of face validation of the survey questionnaire.

\section{References}

1. Government of Karnataka National Health Mission. Detail question and answers on COVID-19 for public. Accessed October 22, 2020. https://www.mohfw.gov.in/pdf/FAQ.pdf 
2. Gupta P, Muthukumar N, Rajshekhar V, et al. Neurosurgery and neurology practices during the novel COVID-19 pandemic: a consensus statement from India. Neurol India. 2020; 68(2):246-254.

3. Yusoff MSB. ABC of content validation and content validity index calculation. Educ Med J. 2019;11(2):49-54.

4. Patil NG, Chan Y, Yan H. SARS and its effect on medical education in Hong Kong. Med Educ. 2003;37(12):1127-1128.

5. Sherbino J, Atzema C. "SARS-Ed": severe acute respiratory syndrome and the impact on medical education. Ann Emerg Med. 2004;44(3):229-231.

6. Fong ZV, Qadan M, McKinney R Jr, et al. Practical implications of novel coronavirus COVID-19 on hospital operations, board certification, and medical education in surgery in the USA. J Gastrointest Surg. 2020;24(6):1232-1236.

7. Mascha EJ, Schober P, Schefold JC, et al. Staffing with disease-based epidemiologic indices may reduce shortage of intensive care unit staff during the COVID-19 pandemic. Anesth Analg. 2020;131(1):24-30.

8. Backer JA, Klinkenberg D, Wallinga J. Incubation period of 2019 novel coronavirus (2019-nCoV) infections among travellers from Wuhan, China, 20-28 January 2020. Euro Surveill. 2020;25(5):2000062.

9. Dutt A. After PM Modi's Covid-19 appeal, footfall in Delhi hospitals decreases. Hindustan Times. Updated March 21, 2020. Accessed October 22, 2020. https://www.hindustantimes.com/india-news/after-pm-s-covid-19-appeal-footfall-indelhi-hospitals-decreases/story-K16LjnQcDuPzxvNaProYtK. html

10. Morris M, Pierce A, Carlisle B, et al. Pre-operative COVID-19 testing and decolonization. Am J Surg. 2020; 220(3):558-560

11. Amin-Hanjani S, Bambakidis NC, Barker FG, et al. Editorial. COVID-19 and neurosurgical practice: an interim report. $J$ Neurosurg. 2020;133(1):3-4.

12. Bambakidis NC, Tomei KL. Editorial. Impact of COVID-19 on neurosurgery resident training and education. J Neurosurg. 2020;133(1):10-11.

13. Bernstein M. Editorial. Neurosurgical priority setting during a pandemic: COVID-19. J Neurosurg. 2020;133(1):18-19.

14. Carter BS, Chiocca EA. Editorial. COVID-19 and academic neurosurgery. J Neurosurg. 2020;133(1):8-9.

15. Choi BD. Editorial. A neurosurgery resident's response to COVID-19: anything but routine. J Neurosurg. 2020;133(1): $16-17$.

16. CovidSurg Collaborative. Elective surgery cancellations due to the COVID-19 pandemic: global predictive modelling to inform surgical recovery plans. Br J Surg. 2020;107(11): $1440-1449$.

17. Fontanella MM, De Maria L, Zanin L, et al. Neurosurgical practice during the severe acute respiratory syndrome coronavirus 2 (SARS-CoV-2) pandemic: a worldwide survey. World Neurosurg. 2020;139:e818-e826.

18. Ghogawala Z, Kurpad S, Falavigna A, et al. Editorial. COVID-19 and spinal surgery. J Neurosurg Spine. 2020; 33(1):1-3

19. Lee ZD, Chyi Yeu DL, Ang BT, et al. Editorial. COVID-19 and its impact on neurosurgery: our early experience in Singapore. J Neurosurg. 2020;133(1):24-25.

20. Prall JA, Davis JD, Jenkins NR. Editorial. Community practice in the time of COVID-19. J Neurosurg. 2020;133(1): $20-21$.

21. Robertson FC, Lippa L, Broekman MLD. Editorial. Task shifting and task sharing for neurosurgeons amidst the COVID-19 pandemic. J Neurosurg. 2020;133(1):5-7.

22. Weiner HL, Adelson PD, Brockmeyer DL, et al. Editorial. Pediatric neurosurgery along with Children's Hospitals' innovations are rapid and uniform in response to the COVID-19 pandemic. J Neurosurg Pediatr. 2020;26(1):3-5.
23. Tomlinson SB, Hendricks BK, Cohen-Gadol AA. Editorial. Innovations in neurosurgical education during the COVID-19 pandemic: is it time to reexamine our neurosurgical training models? J Neurosurg. 2020;133(1):14-15.

24. Fang Y, Zhang H, Xie J, et al. Sensitivity of chest CT for COVID-19: comparison to RT-PCR. Radiology. 2020;296(2): E115-E117.

25. Venkataram T, Goyal N, Dash C, et al. Impact of the COVID-19 pandemic on neurosurgical practice in India: results of an anonymized national survey. Neurol India. 2020; 68(3):595-602.

26. Over 3,000 swab samples pending for over a month for Covid-19 tests in Delhi due to shortage of kits. News18. Updated April 30, 2020. Accessed October 22, 2020. https: //www.news18.com/news/india/over-3000-swab-samplespending-for-over-a-month-for-covid-19-tests-in-delhi-due-toshortage-of-kits-2598733.html

27. Thomas K. Coronavirus test obstacles: a shortage of face masks and swabs. The New York Times. March 18, 2020. Accessed October 22, 2020. https://www.nytimes. com/2020/03/18/health/coronavirus-test-shortages-facemasks-swabs.html

28. Made-in-India coronavirus test swabs to cost only one-tenth of imported ones. The Hindu. May 17, 2020. Accessed October 22, 2020. https://www.thehindu.com/news/national/ india-brings-down-corona-test-swab-price-to-one-tenth/article31607194.ece

29. LABline. Project solves testing swab shortage with 3D-printed swabs. MLO Med Lab Obs. June 2020:22.

30. Centers for Disease Control and Prevention. Serology testing for COVID-19 at CDC. Updated May 23, 2020. Accessed October 22, 2020. https://www.cdc.gov/coronavirus/2019-ncov/ lab/serology-testing.html

31. Hakim AA, Kellish AS, Atabek U, et al. Implications for the use of telehealth in surgical patients during the COVID-19 pandemic. Am J Surg. 2020;220(1):48-49.

32. Kim KH, Choi EH, Kim S-K. Editorial. COVID-19 outbreak and its countermeasures in the Republic of Korea. J Neurosurg. 2020;133(1):29-30.

33. Sun Y, Mao Y. Editorial. Response to COVID-19 in Chinese neurosurgery and beyond. J Neurosurg. 2020;133(1):31-32.

34. Wellons JC, Grant G, Krieger MD, et al. Editorial. Early lessons in the management of COVID-19 for the pediatric neurosurgical community from the leadership of the American Society of Pediatric Neurosurgeons. J Neurosurg Pediatr. 2020;26(1):1-2.

35. Clark VE. Editorial. Impact of COVID-19 on neurosurgery resident research training. J Neurosurg. 2020;133(1):12-13.

36. El-Ghandour NMF, Elsebaie EH, Salem AA, et al. Letter: The impact of the coronavirus (COVID-19) pandemic on neurosurgeons worldwide. Neurosurgery. 2020;87(2):E250E257.

37. Kondziolka D, Couldwell WT, Rutka JT. Introduction. On pandemics: the impact of COVID-19 on the practice of neurosurgery. J Neurosurg. 2020;133(1):1-2.

38. Congress of Neurological Surgeons. Complimentary online education. Accessed October 22, 2020. https://www.cns.org/ onlineed

39. All India Institute of Medical Sciences. Neurosurgery Education and Training School. Accessed October 22, 2020. http:// www.aiimsnets.org/

\section{Disclosures}

Dr. Gupta reports receiving honoraria from Eaisi Inc.

\section{Author Contributions}

Conception and design: Goyal, Dash, Venkataram. Acquisition of data: all authors. Analysis and interpretation of data: Goyal, Ven- 
kataram. Drafting the article: Goyal, Dash, Venkataram. Critically revising the article: Goyal, Dash, Venkataram. Reviewed submitted version of manuscript: Goyal. Approved the final version of the manuscript on behalf of all authors: Goyal. Statistical analysis: Goyal. Administrative/technical/material support: Goyal. Study supervision: Goyal.

\section{Supplemental Information}

Online-Only Content

Supplemental material is available online.

Supplementary Materials 1-3. https://thejns.org/doi/suppl/ 10.3171/2020.9.FOCUS20537.

\section{Correspondence}

Nishant Goyal: All India Institute of Medical Sciences, Rishikesh, Uttarakhand, India.drnishantgoyal@gmail.com. 